\title{
Prácticas de enseñanza que promueven la formación de niños lectores. Un desafío de la era digital*
}

Milena Charbonier**

\section{Resumen}

Este artículo analiza las respuestas que está dando nuestra Escuela a la crisis de la lectura que afecta no sólo a nuestro país sino al Ilamado mundo Occidental, y que es considerada producto de una crisis mucho más profunda: la de la cultura.

La investigación, llevada a cabo entre 2008 y 2009 en una localidad del interior, revela la fragilidad del cimiento en que se instala el maestro, con Planes y Programas que le son impuestos sin verdaderas instancias previas de preparación y discusión, inermes ante los desafíos de una sociedad siempre demandante y poco dispuesta a reconocer los esfuerzos que significa enseñar a sus alumnos a "aprender a aprender" o "aprender para la vida". También rescata las buenas prácticas que promueven la formación de niños lectores en una sociedad marcada por la fuerte presencia de las TIC en la Educación.

\section{Abstract}

The present article analyses the answers our School System is giving to the crisis in reading; a crisis that not only affects our country, but the so called Western World, considering such crisis as the result of a much deeper one; that of culture.

The research, carried out between 2008 and 2009 in a location in mid-country reveals how weak are the foundations on which teachers stand: imposed Plans and Programs with no proper previous study or discussion, a reality that renders school teachers helpless face to the challenges of a society that is over-demanding though unwilling to acknowledge their efforts in teaching their students how to "learn to learn", or to "learn for life".

It also rescues some good practices that promote "readers" -children with reading habits-, in a society marked by the strong presence of ICT in Education.

\section{Introducción}

En las últimas décadas nuestras sociedades ven con preocupación el avance de una situación de crisis de la lectura, que no puede disociarse de una mayor: la crisis de la cultura, fenómeno de carácter internacional. Jean Hébrard (2000) señala que surge a principios de la década de los 50, cuando los sistemas educativos, heredados de los estados del siglo anterior, empiezan a ser considerados incapaces de formar al lector moderno. En esa época se denunciaba también otro fenómeno: la desaparición de la cultura humanística.

La lectura es una actividad personal, familiar, social y cultural. La formación de lectores tiene mucho que ver con el contexto familiar y la socialización a lo largo de la infancia y la adolescencia. Sin embargo, la familia no siempre ha aceptado esta responsabilidad. La escuela primaria se convirtió en el espacio institucional en el que los niños se forman en la lectura, aunque durante mucho tiempo sólo se preocupó por enseñar el mecanismo, devolviendo a la familia la tarea de crear el hábito lector. El problema se hizo irremediablemente visible cuando esos niños no lectores, devenidos en padres no lectores, debieron afrontar tal compromiso. 
Como profesoras de literatura con veinte años de experiencia en la Enseñanza Media, hemos constatado la pérdida, no sólo del hábito lector, sino del caudal de vocabulario de los adolescentes, que es su consecuencia inmediata. Esta doble carencia se convierte en desventaja a la hora de decodificar correctamente los textos de estudio, así como de disfrutar del placer de la lectura de textos literarios. En la actualidad, cada nivel educativo imputa al que le precede la incompetencia lectora de los estudiantes. Sin embargo, algunos chicos se destacan por esa competencia. Por este motivo consideramos importante rescatar aquellas buenas prácticas de enseñanza de la lectura en la escuela primaria.

A continuación se intentará hallar las razones de la crisis de la lectura en los niños de nuestro país. En particular, el cambio que se produce entre la etapa preescolar y la escolar. En la primera, seducidos por el poder de la lectura y ansiosos por apropiarse de él y luego, al aprender sus mecanismos, desinteresados y hasta apáticos.

En el prólogo de "Aprender sí, pero ¿cómo?" (1992), Ph. Meirieu se refiere a las funciones específicas de la escuela y reconoce que, si bien no es el único lugar donde se aprende, sí es el lugar donde se realizan los aprendizajes básicos que condicionan todo lo demás y que nos proporciona las referencias culturales imprescindibles para adquirir nuestra identidad cultural.

En el Diccionario de la Real Academia Española se consignan seis acepciones del término "enseñar". La más generalizada es la primera: "Instruir, doctrinar, amaestrar con reglas o preceptos" (2001, 626). Si bien en los últimos años se ha escrito mucho acerca de nuevas concepciones en torno de la enseñanza, en la práctica, muchas veces, los docentes adoptan sólo el lenguaje y alguna innovación que, a fuerza de repetirse, se vuelve tan rutinizante como en las viejas prácticas. Según Bruner, muchos de los fracasos escolares hallan su explicación en el aburrimiento que generan las prácticas rutinarias y la resolución de problemas que carecen de significación fuera del aula, y que no generan el deseo de aprender. Pero se parece bastante al concepto de "amaestrar con reglas o preceptos".

El Diccionario de la Real Academia Española establece otra acepción: "mostrar o exponer algo, para que sea visto y apreciado". Implica un sujeto que muestra y otro que aprecia. No sólo ve, aprecia, es decir que "reconoce y aprecia el mérito de algo". Se parte de una situación asimétrica con respecto al conocimiento y una relación tendiente a modificarla dando al que aprende las herramientas necesarias para lograrlo. Se trata de provocar el interés del alumno, pero también de demostrar la suma de la experiencia y la capacitación previa del docente en cada situación nueva para lograr una buena enseñanza.

Dentro del campo de la didáctica, las buenas prácticas o buena enseñanza han adquirido un significado propio. Fenstermacher (1986, en Wittrock) considera que el uso del adjetivo "buena" en el concepto no significa simplemente "con éxito" sino que tiene fuerza moral y epistemológica. Desde el punto de vista moral, la buena enseñanza refiere a aquellas acciones docentes que pueden justificarse basándose en principios morales, y que son capaces de provocar acciones de principio por parte de los estudiantes. Desde el punto de vista epistemológico, es buena si lo que se enseña es racionalmente justificable y digno de que el alumno lo conozca, lo crea o lo entienda. 


\section{Concepto de lectura}

Son variados los conceptos que se manejan al hablar de la lectura. Kenneth Goodman (1990) enfatiza en que sin significado no hay lectura. Este especialista precisa que el sentido que va a dar el lector al texto leído va a depender de factores tales como el propósito del lector, su cultura social, sus conocimientos previos. Sintetizando su pensamiento, Goodman dice que toda lectura es interpretación, y lo que el lector es capaz de comprender y aprender a través de la lectura depende de lo que conoce y cree antes de ella. Es por ello que diferentes personas leyendo el mismo texto variarán en lo que comprendan de él, de acuerdo a sus contribuciones personales al significado, ya que sólo pueden interpretar basándose en lo que conocen.

La Asociación Internacional para la Evaluación del Rendimiento Educativo (IEA, International Association for the Evaluation of the Educational Achievement), por su parte, define como lector eficiente a "todo individuo que sea capaz de comprender y emplear aquellas formas de la lengua escrita que sean válidas para la sociedad donde ese individuo se desempeñe" (Fraca, 1993). Mientras que para Ralph Steiger el lector es mero decodificador del sentido dado por el autor al texto, Isabel Solé (1994) agrega los objetivos de la acción de leer, se trata de "leer para...".

Michèle Petit insiste en el rol que le cabe al entorno familiar del niño en su proceso de aprendizaje. Ella ha destacado la lectura como creadora de sentidos, reforzadora de identidades y reparadora de las cicatrices que algunos hechos personales, familiares o colectivos dejan en los seres humanos. Ha dirigido sus investigaciones intentando descubrir de qué manera, apropiándose de textos, las personas "elaboran un espacio de libertad a partir del cual pueden darle sentido a sus vidas, y encontrar la energía para escapar de los callejones sin salida en los que estaban bloqueados" (Petit, 2001, 31). Según Patricia Ratto $(2003,25)$ "leer es construir sentido". La novedad de esta definición es la actitud del lector, que abandona su pasividad para construir. El sentido no está en el texto ni en la lejana intención del autor.

Todas estas definiciones parten de la "teoría transaccional" desarrollada por Louise Rosenblatt en su libro de 1978 "The reader, the text, the poem". Para ella la lectura es un suceso particular en el tiempo que reúne a un lector y a un texto particulares en circunstancias también particulares. El lector adquiere su carácter de tal en virtud del acto de lectura y es a través de éste que el texto adquiere significación. En el proceso de transacción, lector y texto son mutuamente dependientes y de su interpretación recíproca surge el sentido de la lectura. El foco de atención del lector durante la transacción de la lectura es sumamente importante para Rosenblatt, porque va a determinar dos posturas diferentes frente al texto: la estética y la eferente. Cuando el lector adopta la primera, permanece absorto en lo que piensa y siente, en lo que vive a través y durante el acto de lectura. En la segunda postura (el término "eferente" significa etimológicamente "llevar, sacar algo"), la atención del lector está centrada en lo que retiene después de leer un texto. El lector así dirige selectivamente su atención hacia unos elementos e ignora otros. En la lectura estética el sentido que construye el lector está fundido con el sonido, el ritmo, las asociaciones; se diría que es un sentido experimentado, vivido por el lector en el acto de leer. Esta lectura que le permite desarrollarse, es la que hará al niño un usuario competente de la lengua, un lector eficiente y un ciudadano crítico y comprometido con su tiempo. En el modelo transaccional, la lectura estética y la eferente son dos modos coordinados o paralelos. Según esta teoría, a medida que el lector transactúa con el texto se produce la adopción, consciente o inconscientemente, de una postura predominante que afectará el proceso de lectura de dicho texto. Éste es el aporte más importante realizado por Rosenblatt, en particular por las repercusiones que el mismo tiene para la práctica pedagógica en el campo de la lectura. 
La irrupción de las nuevas tecnologías de la información y la comunicación ha generado nuevas concepciones sobre la lectura. Ya no se duda de que las mismas seguirán siendo uno de los instrumentos más importantes de acceso al conocimiento. Retomando las palabras de Millán, son "la llave del conocimiento en la sociedad de la información" (2000), pero exigen el dominio de nuevos saberes, conocimientos y habilidades. Asimismo, se las reconoce "fundamental para comunicarnos, relacionarnos, gozar, pensar, aprender, construir representaciones sobre el mundo y sobre nosotros mismos y atribuir sentido a las experiencias propias y ajenas" (Coll, 2005). Pero los investigadores señalan también que estamos ante la redefinición de las prácticas de lectura y de la cultura escrita. Los lectores de hoy deben interactuar con el libro tradicional, el libro electrónico, la escritura manual y la producción de textos electrónicos, por ello Chartier (1994, citado por Coll) destaca la importancia de comprender que el acto de lectura es contextual y que puede seguir diversas prácticas.

Las nuevas concepciones de lectura conllevan su propia terminología. Así se retoma el concepto de hipertexto, acuñado por Nelson en los años sesenta, resignificado por Landow como "un tipo de escritura no secuencial, a un texto que se bifurca, que permite que el lector elija y se lea mejor en una pantalla interactiva" (1995). También Burbules y Callister definen el hipertexto como "un conjunto de recursos informáticos (que en la actualidad comprende millones de páginas) conectados por enlaces, que mediante clics nos llevan de un sitio a otro, a menudo de manera no lineal y sin seguir una jerarquía..." (2001). Para estos autores, el hipertexto se presenta como una herramienta central que supone cambios en las formas de conocimiento, pero exige un nuevo actor, el hiperlector, que debe ser capaz de realizar sus propias lecturas, sus propias elecciones de lo que encuentra en la red.

En una entrevista para la revista Monitor, Emilia Ferreiro deja claro que se sigue leyendo pero que el verbo leer tiene nuevas connotaciones. Recuerda que la lectura en pantalla difiere de la lectura de un texto impreso por su falta de "materialidad", la presentación vertical de la página, la ausencia de página en el sentido estricto y hasta por la forma de "hojear" cuando se exploran hipertextos.

\section{La enseñanza de la lectura}

Isabel Solé (1994, en Quintana, 2004) señala que el proceso de la lectura es interno, inconsciente, y del que no tenemos pruebas hasta que nuestras predicciones no se cumplen. Ese proceso debe asegurar que el lector comprende el texto y que puede ir construyendo ideas sobre el contenido extrayendo de él lo que le interesa. La forma de hacerlo es a través de una lectura individual, precisa, que avance y retroceda, que le permita detenerse, pensar, relacionar la información nueva con el conocimiento previo que posee, decidir qué es lo importante y qué lo secundario.

Si se usa la palabra "enseñar" en el sentido de "mostrar algo", la característica de cosa impuesta desde afuera desaparece. Desde el punto de vista de las nuevas concepciones, esta forma de enseñar a leer implica mostrar al niño la manera en que los adultos utilizan la lectura.

Silvia Castrillón (1989) destaca la importancia de que el niño viva y aprenda la lectura como parte de su vida cotidiana, y no sólo como instrumento de aprendizaje escolar, pues el niño contemporáneo se encuentra sometido a los estímulos de un mundo de imágenes, de informaciones, de datos, que se le presentan de forma caótica, sin discriminación ni orden. "Es preciso ofrecerle herramientas de análisis que le permitan organizar la yuxtaposición anárquica de la información que se ofrece y puntos de partida desde los cuales el niño pueda construir el conocimiento que controle, analice y critique" (Castillo Burgos, 2002, 2). El libro, el texto escrito, encontrará allí su primer papel, como instrumento de organización, de comprensión 
y de síntesis que "permite al niño tomar posesión de la información, que reafirma su libertad y su autonomía y que le permite cambiar su papel de receptor pasivo de la información a interlocutor activo" (Castrillón, citada por Castillo Burgos, 2002, 2). Pero no debe olvidarse la afirmación de Solé (1994 citada por Quintana, 2004): "leer es mucho más que poseer un caudal de estrategias. Leer es sobre todo una actividad voluntaria y placentera y enseñar a leer debe tener esto en cuenta".

Al niño, por lo general ansioso por aprender, se le enfrenta a un sistema de aprendizaje que ignora por completo su experiencia de vida, y que presenta el lenguaje escrito en forma de letras, sílabas y frases sin sentido y organizado en una secuencia impuesta por el adulto por niveles de dificultad que no le dicen nada. La escuela da un carácter artificial a lo escrito, que aparece allí sólo como una materia para la enseñanza, separado de todo contexto de significación, divorciado de la vida.

Los niños deben ser motivados para aprender. Aprender es su oficio. No pueden dejar de aprender porque no pueden dejar de crecer. Todos los objetos (materiales o conceptuales) a los cuales los adultos dan importancia son objeto de atención por parte de los niños. Si perciben que las letras son importantes para los adultos (sin importar por qué y para qué lo son) van a tratar de apropiarse de ellas. Las encuestas coinciden en un hecho: si el niño ha estado en contacto con lectores antes de entrar a la escuela aprenderá más fácilmente a escribir y leer que aquellos niños que no han tenido contacto con lectores.

\section{Formación de lectores}

Educar ciudadanos autónomos, con criterios para tomar decisiones sobre sus destinos, con avidez por aprender y con comportamientos sociales solidarios, es el objetivo primordial de los adultos encargados de guiar a los niños. Para lograr esto es necesario remontarse a lo básico: a la formación de lectores.

Si la intención es lograr que los niños lean y lean con placer, es necesario empezar con actividades conscientes para promover la lectura mediante "la realización de un conjunto de acciones sucesivas y sistemáticas de diversa naturaleza, encaminadas todas a despertar o fortalecer el interés por los materiales de lectura y su utilización cotidiana, no sólo como instrumentos" (Sergio Andricaín, citado por Martínez Barrientos, 2003, 4).

Por una parte Michèle Petit (2006) propone algunas actividades para que el niño se convierta más adelante en lector: la familiaridad física precoz con los libros, la posibilidad de manipularlos para que esos objetos no lleguen a investirse de poder y provoquen temor. También son importantes los intercambios en torno a esos libros y las lecturas en voz alta, en donde los gestos de ternura y los colores de la voz se mezclan con las palabras de la lengua en la narración, aunque especifica que no hay recetas para asegurar la conversión de las personas a la lectura, sólo factores propicios para el desarrollo de la misma. Por otra parte, la relación con la lectura tiene que ver con la estructura psíquica y con cierta manera de actuar respecto a la carencia y a la pérdida. La lectura, y en particular la literaria, tiene que ver con la experiencia de la carencia y de la pérdida. Cuando uno pretende negar la pérdida, evita la lectura. O trata de dominarla. 


\section{La crisis de la lectura}

Emilia Ferreiro (2005) advierte que todos los problemas de la alfabetización comenzaron cuando se decidió que escribir no era una profesión sino una obligación, y que leer era una marca de ciudadanía y no de sabiduría. Leer y escribir son, de acuerdo a esta autora, construcciones sociales. La democratización de la lectura y la escritura vino acompañada de una radical incapacidad para hacerla efectiva. Se creó una escuela pública obligatoria para permitir el acceso a los saberes, para formar al ciudadano consciente de sus derechos y sus obligaciones, pero sigue tratando de enseñar técnicas: del trazado de las letras, de la correcta oralización del texto.

Según Lerner, la escuela se enfrenta a una paradoja, es decir, asume la responsabilidad de enseñar a leer y a escribir, pero al transformar el objeto de enseñanza (en aras de la selección de lo que se tiene que aprender) cambia el sentido de las prácticas sociales, que se convierten en una actividad muy diferente a lo que realmente es fuera de la escuela, cultivando con ello una especie de disociación con la realidad o esquizofrenia educativa, es decir: lo que el estudiante aprende en la escuela no tiene que ver con lo que hace cotidianamente en su vida.

\section{Enseñanza de lectura en Uruguay}

En 2009 entró en vigencia el nuevo Programa de Educación Inicial y Primaria que había comenzado a discutirse en setiembre de 2008 a nivel de las escuelas del país. El mismo "se formula desde el marco de las Ciencias de la Educación". La fundamentación general retoma el concepto de educación como terreno de tensiones y la escuela pública como el "lugar de vigencia de lo público", al decir de Carlos Cullen.

En el apartado destinado a la lectura, ésta se define como un "proceso de construcción de sentido, producto de la transacción entre el lector y el texto, que pone en juego los conocimientos lingüísticos y enciclopédicos del primero con las pistas lingüísticas codificadas del segundo". Incluye el concepto de "literacidad", traducción aceptada desde comienzos del siglo XXI del inglés "literacy", y que implica una "lectura crítica del contexto socio-histórico en que el texto considerado tuvo origen y ha circulado o circula, en relación con la ideología que reposa en los significados, partiendo de la base de que no es palabra neutra".

Ser lector, en la nueva propuesta educativa, es saber obtener información general sobre un tema, encontrar información específica, entender un manual de instrucciones, disfrutar con un libro, reconocer y apreciar distintos tipos de texto, tener la oportunidad de elegir lo que le gusta leer, saber explicar a otro las ideas principales de un texto, realizar inferencias, saber estudiar y disfrutarlo. "La Escuela debe enseñar al niño a realizar las inferencias que le permitan identificar la intención del discurso y las voces que aparecen en el mismo, la ideología del autor, el mensaje global... los subtemas, la información explícita e implícita, así como lo no dicho".

Con respecto a la enseñanza de la lectura, en primer lugar se vincula con la enseñanza de la escritura, dado que, citando a Frank Smith, "[...] hace falta leer de una manera determinada para aprender a escribir; tenemos que leer como un escritor". Entendida como interpretación de la realidad, se aconseja extender la enseñanza de la lectura "a todo el currículo escolar y en el tránsito de toda la educación formal".

A continuación se sugiere la utilización de estrategias "para que el alumno pueda planificar su tarea de lectura de acuerdo con su interés o necesidad, facilitar la comprobación, la revisión y el control de lo que se lee, y tomar decisiones adecuadas en función de los objetivos que persigue". 


\section{Enseñar con TIC}

Según Nicholas Negroponte, la Era Digital es comparable a una fuerza de la naturaleza que "no se puede negar ni detener" y que, gracias a sus cuatros poderosas cualidades -descentralizante, globalizante, armonizante y liberalizante- está destinada al triunfo (citado por Cabello, 2006, 42). Es innegable la importancia de Negroponte en el mundo de la investigación científica, la producción tecnológica y la circulación masiva de nociones relacionadas con la revolución digital a principio de los años noventa.

Cuando se pide a la escuela que se apropie de las TIC, pocas veces se tiene en cuenta la revolución que ello implica: reorganizar los espacios y tiempos, repensar los perfiles de los docentes, conocer las tecnologías digitales y reconocer los miedos de los adultos en general y los maestros en particular. Asimismo, deben repensarse las formas de transmisión de los saberes que se ponen en juego en las aulas. Recordemos que Cullen (2005) habla de la necesidad de resignificar socialmente a la escuela en un mundo en que los conocimientos "circulan socialmente desnormalizados". Para que la integración pedagógica de las TIC se convierta en una oportunidad de inclusión, debe ser pertinente y significativa para quienes participan de ella.

La clave está en enseñar a enseñar. Linda Harasim, representando la propuesta del BID (Banco Interamericano de Desarrollo) dice que deben concebirse y ensayarse nuevas pedagogías, entornos en línea y modelos didácticos. Como señala Marcela Czarny, los docentes han dejado de ser "fuente de todo saber"para asumir un desafío mayor: "ayudar a que los alumnos transiten activamente el camino de aprender. En un mundo hiperinformado como el nuestro, es necesario que los niños vayan construyendo las herramientas necesarias para poder relacionar la información obtenida con datos y esquemas cognitivos previos, para poder producir saltos cualitativos en el hecho de conocer y para poder comprender el mundo a partir de la integración de los viejos y nuevos conceptos" $(2000,126)$.

La nueva metodología se inspira en las teorías constructivistas, según las cuales el alumno es agente activo de su propio aprendizaje. En la pedagogía tradicional el docente tenía la respuesta y el alumno se limitaba a reproducirla. Ahora se trata de que el alumno investigue en busca de respuestas, así podrá producir nuevos aprendizajes de forma autónoma en el futuro, en el marco de una formación continua; "aprenderá a aprender".

Desde 2001 existe en Uruguay un Programa de Conectividad Educativa que abarca todos los subsistemas de la ANEP (Administración Nacional de Educación Pública). Por él se suministró a los Centros Educativos el equipamiento informático necesario. El Proyecto Ceibal (Conectividad Educativa de Informática Básica para el Aprendizaje en Línea) se realiza dentro del marco del Plan de Inclusión y Acceso a la Sociedad de la Información y el Conocimiento que integra la Agenda Digital del Gobierno para ser aplicado en el ámbito de la ANEP. El mismo procura facilitar a la mayor parte de los uruguayos, a través de los alumnos de las escuelas públicas, el acceso a la información computarizada y al trabajo en red entre los domicilios, así como entre éstos, los maestros y las escuelas (Portal Educativo Ceibal, 4).

Dentro de los objetivos del Programa se encuentra la inclusión digital a fin de disminuir la brecha digital existente respecto de otros países y de los ciudadanos del país entre sí. Se trata de incorporar tecnología y accesibilidad a los centros así como garantizar su uso, la formación docente, la elaboración de contenidos adecuados y la promoción de la participación familiar y social. 


\section{Metodología}

La investigación se llevó a cabo en una ciudad del interior del país con dieciséis mil habitantes y nueve escuelas primarias. La metodología empleada fue de corte cualitativo, lo que permite comprender la realidad, sus significaciones e intenciones humanas. Dentro de esta perspectiva, se eligió una aproximación interpretativa por valorar la visión que los sujetos tienen de ellos mismos y los significados de sus comportamientos.

Se intentó un estudio profundo de los datos obtenidos a través de las encuestas y entrevistas de formato semi-estructurado no secuencializado, las que fueron transcritas en su totalidad para luego ser analizadas en grupos de acuerdo a un criterio de exhaustividad, evaluándose en cada caso elementos de la población que se consideran importantes, de acuerdo a Goetz y Le Compte (1988). Para lograrlo se entrevistó y encuestó a distintos representantes de las instituciones educativas, a fin de obtener representatividad y de saturar teóricamente la muestra con los datos que confirmaran empíricamente las categorías estudiadas, como explican Glaser y Strauss (1967). Se consideraron los siguientes:

. Alumnos egresados recientemente de Educación Primaria

. Docentes de las esscuelas de la ciudad

. Docentes participantes de la Investigación

. Maestros Directores

El trabajo de campo consistió en la realización de encuestas a los estudiantes de primer año de enseñanza media de los liceos y escuela técnica de la ciudad, entrevista a una Maestra Directora y una docente experta, un cuestionario escrito a todos los maestros que trabajaban en la ciudad en 2008 suministrados a través de los directores de cada escuela, la observación de clases y entrevistas posteriores con los docentes involucrados.

Culminado ese proceso se decidió trabajar con dos escuelas, una de nivel medio-alto y otra de contexto social crítico. Se logró una entrevista con una Maestra Directora y la participación de seis maestros comunes que abarcaron todos los niveles de la educación escolar: uno de primer año, uno de tercero, dos de cuarto y dos de quinto año.

El cuestionario a los estudiantes permitió conocer la mirada de los adolescentes sobre la lectura y sus dificultades. La primera sorpresa surgió de la lectura de los resultados de la encuesta. Se obtuvieron datos de 248 estudiantes de los cuales el $73 \%$ se manifiesta interesado en la lectura. Con respecto a las dificultades para leer, sólo el $18 \%$ admite poseerlas frente al $60 \%$ que no las reconoce. En cuanto a los docentes que influyeron en su hábito lector no fue posible considerarlo como indicador para la selección de los maestros participantes debido a la multiplicidad, así como a la movilidad de los mismos.

La entrevista a la Maestra Directora permitió reconstruir la historia de la enseñanza de la lectura en nuestro país en los últimos treinta años, echando luz sobre algunos aspectos que no habían sido tenidos en cuenta en el marco teórico de la investigación.

\section{Los maestros tienen la palabra}

¿Cómo se traducen estas respuestas en la dedicación real de los maestros a la enseñanza de la lectura o a la formación de lectores? De las cincuenta y seis respuestas recibidas sólo nueve tienen en cuenta la formación de lectores competentes en tanto motivo de recreación, quienes son más puntillosos afirman dedicarle media hora semanal, con la excepción de una maestra de primer año que consagra de una a dos horas a la lectura placentera. El resto manifiesta trabajar entre dos y cinco horas semanales con lectura relacionada con la comprensión o incorporada a otras áreas como Matemática, Ciencias Sociales o Ciencias Naturales, técnicas de estudio, lectura de consignas o situaciones problemáticas. 
La mayoría de los maestros, entonces, sigue considerando la lectura como un conjunto de habilidades, un proceso que puede ser dividido en sus partes componentes para ser enseñado y cuyo resultado final debe ser un alumno lector. Mientras tanto, éste permanece ajeno al texto, que es el que da sentido a lectura. Sólo una minoría realiza prácticas más acordes con las nuevas concepciones de lectura, que la considera un proceso interactivo y transaccional. Recordamos que para Lorenzo (1997), ambas concepciones se complementan, ya que para ambas la lectura es un proceso indivisible y global, y el lector es constructor del sentido del texto a través de su interacción con él. Mientras lector y texto transactúan, el primero adopta una postura -eferente o estética- que afectará el proceso de lectura de ese texto.

\section{¿Qué se enseña cuando se enseña lectura?}

Como lo señalaba el antiguo Programa, la lectura era considerada un instrumento que los niños debían adquirir en forma plena. Para ello la escuela debía dedicarse a enseñar "mecánica lectora, comprensión lectora y fundamentalmente, despertar el gusto por la misma". Pero esta concepción fue variando, como lo demuestra la Circular No 8 de 2006 en la que, retomando las palabras de Isabel Solé, la lectura es conocimiento e instrumento de conocimiento, así como medio para el placer y la distracción. Si bien esta Circular es mencionada constantemente por los docentes porque explicita "las variadas estrategias para la enseñanza sistematizada de la lectura", las prácticas siguen demostrando una mayor dedicación a su enseñanza como instrumento, como técnica. Como señala Lerner $(1996,7)$, la lectura es, en la escuela, más un objeto de enseñanza que un objeto de aprendizaje. No se toma en cuenta al alumno, para quien el propósito de ese aprendizaje no tiene valor, por lo que no generará el "enigma" que valora Meirieu (1992); el deseo de seguir aprendiendo más allá del maestro. Lo que hace, entonces, es "seguirle el juego a la escuela" logrando un "conocimiento ritual, que sólo sirve para la escuela" (Perkins, 2001, 31-32).

\section{Maestra, ¿verdad que vos sabés todo?}

Carlos Cullen (2005) nos recuerda que hace tiempo que la escuela dejó de ser el "templo del saber" y que "saberes y conocimientos [...] circulan socialmente desnormalizados" $(2005,46)$. Sin embargo, Davini (2005) nos advierte sobre las tradiciones, "configuraciones de pensamiento y de acción que [...] están institucionalizadas, es decir incorporadas a las prácticas y a la conciencia de los sujetos" $(2005,20)$. Consideramos que una de ellas es la del "maestro-superhéroe", con todas las respuestas para todas las demandas de sus alumnos. En las observaciones realizadas sólo en dos ocasiones pudimos asistir a la búsqueda del experto. En el caso de la Maestra D ( $5^{\circ}$ año), el trabajo con un texto ("Los castillos de arena", tomado de la revista "Muy interesante") derivó en la posibilidad de invitar a un profesor de física y otro de química para que les explicara los conceptos de "electrostática", "polos", "carga positiva y negativa", tras una ampliación de conocimientos buscando en Internet. Pero también se consideró la posibilidad de preguntar a un albañil por qué se sostienen los castillos de arena.

En la entrevista posterior a la maestra, esta explicó que "no lo había planificado así (...) Surgieron preguntas de ellos y había que contestarlas. Eran los saberes previos de ellos, sus saberes cotidianos de ver cómo se prepara la mezcla porque la mayoría de los papás trabajan en changas. ¿Qué chiquilín de éstos no ha acarreado un balde con mezcla, por ejemplo? ¿O ha llevado arena en un carro con el padre o el abuelo?". 
La Maestra C ( $4^{\circ}$ año) es una gran lectora, lee textos recreativos a sus alumnos y a los de otras clases y logra la atención de todos ellos. Sin embargo, dos veces al año invita a una profesora de declamación y a su alumna más adelantada, quienes leen textos que los niños conocen y otros nuevos.

M: Ayer estuve hablando con N., ¿quién era?

A: La señora que vino a decir poemas.

M: Y que es alumna de la Sra. S. Van a volver. Tenemos que elegir qué texto queremos: de los textos que hemos trabajado, cuál les gustaría a ustedes.

Por un lado, a juzgar por la actitud con la que los niños sugieren posibles textos, narrativos y poéticos, puede notarse que se trata de una actividad placentera. Incluso cuando alguien menciona "Cartas a Nicolás" otro alumno aclara "Cuando dice 'Ah, Nicolás, quién tuviera el corazón..."'. Esto demuestra, además, que la maestra ha logrado que los niños elaboren su propio proyecto de lectura, centrándose en "aquellas frases que lo impactan por su belleza, su precisión o su ironía", en palabras de Delia Lerner (1996). Pero por lo común puede notarse la reticencia a reconocer las propias limitaciones. Por otro lado están las maestras de Educación Inicial, quienes parecen más dispuestas a recibir a sus colegas en el aula, en particular en tareas relacionadas con las computadoras. En la encuesta realizada a los docentes, al preguntárseles si habían incorporado las TIC a sus prácticas, una de ellas contestó: "Los niños de mi grupo usan y manejan los recursos tecnológicos (las computadoras del Plan Ceibal) en grupos de pares con niños de segundo año. En el último encuentro se conectaron a Internet en la página Garabato y seleccionaron Pictograma para elegir y leer cuentos".

También en la entrevista a la docente experta se mencionó esa labor conjunta: "Ahora ya le dije a la maestra de jardinera, que no tienen computadoras, que la semana que viene vamos a ir con los niños y las XO. Vamos a empezar a enseñarles las partes como hice con los míos, y vamos a empezar a ver los diferentes programas, hacer alguna descripción de algún animalito, de algún tema emergente que surja en el momento que ellos estén entusiasmados. El año pasado trabajé así porque considero que es una ayuda para ellos mismos. Fue muy diferente recibirlas este año que el año pasado. El año pasado los chiquilines no sabían nada, este año los alumnos las vieron el año pasado".

Puede decirse que, de alguna manera, la escuela se va transformando en la "comunidad de aprendices" que implicaba Simonds (citado por Santos Guerra, 2000), aunque se trata de un proceso lento y doloroso, en el que cada actor debe reconocer sus limitaciones y aceptar la ayuda de sus pares.

\section{En busca del tiempo perdido}

En su afán de enciclopedismo, la escuela olvidó que para que el niño aprenda, primero tiene que tener el deseo de hacerlo, poniendo el acento en la técnica y resignando el entusiasmo generador. En esa pedagogización de la lectura, se perdió el sentido estético, convirtiéndose en lo que Perkins denominó "conocimiento inerte" que, en "La escuela inteligente" (2001, 33), define como el conocimiento adquirido que el alumno es incapaz de aplicar en las situaciones en que realmente lo necesita. El resultado fue esta crisis de la lectura que en los últimos años se empezó a combatir. La lectura placentera se ha convertido, en nuestro país, en una cuestión de políticas educativas.

La "buena enseñanza" es la que genera deseo de saber y produce satisfacción. Provoca una relación enriquecedora en dos sentidos ya que expande la mente del docente y del alumno. Cuando se trata de la enseñanza de la lectura, ésta tiene que llegar de manera interesante y placentera, puesto que el niño pertenece a la cultura de la imagen, más fácil de aprehender. 
A pesar del tiempo que los maestros afirman dedicar a la lectura, en la observación sólo dos profesionales utilizaron expresiones relacionadas con el placer: "invitar", "disfrutar", "compartir". Aun así, fue posible ver la realización de esa lectura placentera por parte de los alumnos en otros dos grupos.

Observemos el caso de la Maestra B ( $1^{\circ}$ año). Su planificación de la primera clase que visitamos establecía como uno de los objetivos "construir paulatinamente el hábito lector". Cuando regresan del recreo, la maestra se sienta en una sillita al frente de la clase y los niños lo hacen en torno a ella en el suelo. La docente, luego de mostrarles un libro y ayudarlos a recordar otros textos leídos del mismo autor, dice: "Como hace tanto calor yo voy a leerles un cuento para disfrutar [...]: "Por el camino de la playa". ¿Por qué habré elegido este cuento?"

Luego de la lectura y de un breve comentario sobre el tema, pasa a la tarea siguiente, ordenar otro cuento de ese libro que está dividido en párrafos en distintas cartulinas de color. Organiza grupos de cinco niños que van leyendo los párrafos que les tocaron y los van ordenando. Al final oralizan la estrategia empleada para reconstruir el texto.

En la tercera observación de clase la maestra propone ver la caja de los recomendados donde encuentran una breve nota de otro grupo de $1^{\circ}$ año que les sugiere la lectura de un cuento y argumenta los motivos de la elección. Mientras los niños lo buscan en la caja de cuentos, la maestra toma una sillita y todos se ubican como en la clase anterior. Se produce el siguiente diálogo:

M: Juan, ¿quieres leer tú?

Juan: Sí.

M: Bueno, empiece, fuerte.

La maestra y Juan intercambian lugares y Juan comienza a leer, mostrando las láminas que trae el libro, mientras sus compañeros lo escuchan con atención.

Recordamos que Tonucci (1989) señalaba como error frecuente la práctica prematura de la lectura en voz alta. En la Circular No 8 se retoma esa idea indicándose que "el niño sólo debería oír leer en voz alta buenos modelos" y que no es conveniente exponerlo "a leer en voz alta cuando tiene dificultades para oralizar un texto". La Maestra B va traspasando el control de la lectura a sus alumnos de manera natural, invitando a uno de ellos a leer conociendo el nivel que el mismo ha alcanzado, pero dándole la oportunidad de negarse también. En otra circunstancia invita a leer breves narraciones a otros grupos. Esta actividad de aula expandida es justificada por la docente como una estrategia para la práctica de lectura sin que los niños se aburran: "Todo lo lúdico los atrapa y se hace mucho más ameno". Carlos Cullen (2005) señala la importancia de lo lúdico en el aprendizaje porque a través de él se generan las reglas sociales de producción y de comunicación. Por lo tanto el tiempo de aprendizaje debe ser de creación y de gozo.

La maestra está provocando un aprendizaje significativo, ya que los alumnos están motivados por el objeto de estudio. De acuerdo a la perspectiva constructivista la docente está colaborando en la formación de la imagen de cada uno de los niños dándoles la libertad de leer o no, de acuerdo a las posibilidades de fracaso que creen tener. No hay exposición sino invitación, una forma humanista de concebir el aprendizaje escolar.

La maestra $\mathrm{D}\left(5^{\circ}\right.$ año), por su parte, también se guía por la Circular mencionada que dice, en la página 2 "La lectura placentera se asocia generalmente al nivel estético-recreativo, no considerándose el placer que otorga el aprender en todas las disciplinas, el descubrir a través de la lectura una nueva posibilidad que ofrece determinado programa informático o un artefacto doméstico". 
En la primera clase observada reparte unas fotocopias con un texto diciendo "Por ahora los voy a invitar solamente a leer el título y nada más. [...] "Los castillos de arena". ¿Quién ha hecho castillos de arena?". A continuación los niños, siempre dirigidos por su maestra van mencionando las variadas sensaciones que les provoca la arena, las imágenes mentales. Le sigue el retorno a la lectura en busca de sus saberes previos, relacionándola con el uso de la arena por parte de los albañiles para hacer "la mezcla", la importancia de la humedad, el sol, el piso, las manos para afirmarla, la posibilidad de emplear moldes, lo que lleva a asociarlos con la cocina y las ladrilleras. Al fin, tras sugerir que "no nos vayamos del tema" la clase continúa. '"Cualquier chico...' así comienza la lectura que les trajo la maestra para compartir. Ahora vamos a leerla y a disfrutar cada uno de la lectura en silencio".

La maestra moviliza los conocimientos previos de sus alumnos ya que para que el aprendizaje sea significativo, el alumno debe poner en juego los conceptos, ideas y percepciones que, según Ausubel (1973), posee en su estructura cognitiva. A partir de esta concepción el alumno pasa a ser quien procese la información. Asimismo, cuando llegó la propuesta de lectura, los niños ya estaban motivados para hacerlo y descubrir qué relación podían tener con todas esas ideas y asociaciones que habían ido surgiendo.

En la entrevista posterior explica: "Es que yo trabajo la oralidad desde ahí, y más con esos chiquilines que tienen esa pobreza de vocabulario. Además, muchas veces, si no es en la escuela, no tienen otro ámbito donde hablar ni a quién contarles las cosas. Muchas veces, dándoles un lugar en la escuela, hay que ver lo que los chiquilines te cuentan. La oralidad trabajada desde ahí en todo momento". Lo que ha hecho es generar el placer de aprender. Casi sin darse cuenta los alumnos fueron analizando el tipo de texto que tenían en sus manos, las propiedades físicas de la arena, la electrostática, utilizaron el diccionario cuando se enfrentaban a palabras desconocidas, trabajaron en equipo releyendo y opinando sobre el tema, nombraron un secretario o secretaria para que comunicara sus descubrimientos al resto del grupo, buscaron información sobre los castillos de arena en Internet, guiados por la maestra, quien les hacía volver al tema cuando la búsqueda se desordenaba. "¿Sirve esto que estás copiando? ¿Te aclara la pregunta?", siempre alentando la tarea y valorando los logros de cada uno. Al terminar el trabajo se resumió lo realizado. Podría decirse, siguiendo a Ausubel (1976), que los aprendizajes realizados fueron significativos, en tanto los alumnos estuvieron en todo momento motivados para aprender, el tema despertó su interés, la maestra les transmitía confianza y el clima de trabajo era muy distendido, lo que contrasta con la descripción que la misma hizo del grupo al momento de hacerse cargo de él, cuya característica principal eran los problemas de conducta. Asimismo, con el cierre que hizo del tema, actuó como mediadora entre los niños y sus aprendizajes trabajando en lo que Vigotsky $(1978,133-134)$ denominó "Zona de Desarrollo Próximo".

Cuando la invitamos a reflexionar sobre su forma de encarar la lectura en clase respondió: "Sí, yo en todas mis clases los invito a leer. Que veo que algunos me dan bolilla y otros no, quiere decir que están más habituados que otros, pero eso es algo que con el tiempo yo me tengo que ir ganando. Porque no viene a leer por placer el chiquilín cuando vos lo recibís el primer día de clase. Salvo que hayan estado habituados los años anteriores".

En todas las clases observadas de la Maestra F, la misma trabajó con textos narrativos: "Sucedidos/1" de "El libro de los abrazos" de Eduardo Galeano, "Hombre quieto" de "Cuentos para oír, 5" de Ezequiel Mattos e "Historia de dos que soñaron" de autor anónimo. En todos los casos los niños demostraban su interés con comentarios como "Maestra, yo se lo leí a mi madre" en el primer caso; la relación con Don Quijote de la Mancha en las predicciones sobre el segundo texto y con las enseñanzas familiares al hablar del protagonista: 
A: Verdaderamente no me gustaría [ser como él], porque si no, no vas a ser nadie.

M: Sobresaliente.

A: Eso me dice mi madre siempre.

M: Excelente tu madre.

A: A lo primero está bien porque no hacés nada, pero después no te sirve.

Cuando los alumnos iban terminando una tarea propuesta por la maestra en una hoja suelta que debían entregar, y mientras esperaban a sus compañeros, fueron sacando libros de sus mochilas y se dedicaban a leer con naturalidad a partir de los señaladores ubicados en su interior. Sobresalían los escritores para niños y adolescentes más reconocidos en la actualidad: Berocay, Velando, Martínez, Helguera, Ivaniev.

Por su parte, la Maestra C ( $4^{\circ}$ año) ha ubicado, en el fondo del estrecho salón, una mesita con diarios, revistas y libros. A su vez los niños pueden pedir otros textos que están en una biblioteca bajo llave (se trata de un salón compartido con otro grupo) para leer allí o llevar a sus casas.

En las predicciones a partir del título, que anteceden al trabajo con el texto "El dueño del higueral", surgieron las asociaciones con "El vendedor de naranjas", leído con anterioridad, y las "Cartas a Nicolás" que en realidad "hablaba de un pájaro". Tras la lectura silenciosa se escuchaban demostraciones de interés por ese texto "buenazo" y "divertido". La maestra repartió un cuestionario para sondear la comprensión de los alumnos, dio las indicaciones correspondientes y luego se sentó en su lugar leyendo un libro. Si bien parecía muy concentrada en su lectura, mostrándose como modelo a seguir, estaba atenta a las dudas de los chicos aunque intentando provocar su independencia. Cuando los alumnos terminaron, leyó el cuento en voz alta mientras algunos alumnos la seguían y otros sólo escuchaban y disfrutaban de esa lectura. En el comentario general, algunos preguntaron el significado de alguna palabra, intentaron ubicar dónde se desarrollaba la historia y no faltó quien recordara, al hablar de fantasmas, los zombis de la novela de Berocay que la maestra les estaba leyendo en esa época. Además opinaron sobre las actitudes de los personajes.

En la tercera visita los niños trabajaron con un fragmento de "Harry Potter y la cámara secreta". La maestra sólo explicó la consigna hasta asegurarse de que todos habían entendido y los dejó trabajar solos. Luego pasó a comentarnos la evolución de los alumnos: "Ya tienen esa habilidad de saber si necesitan conocer lo que significan todas las palabras o no [...] Ellos tienen que tratar de entender desde el texto. Que me parece que es un esfuerzo que ellos tienen que hacer y me parece que está mejor. [...] Y que ellos estén trabajando en silencio un viernes, a las cinco de la tarde, me da la pauta de que les gusta trabajar así y lo entienden". Creemos que estas actividades se inscriben en la definición de Isabel Solé (citada por Quintana, 2004) en cuanto a que la lectura va más allá de la posesión de un caudal de estrategias. "Leer es sobre todo una actividad voluntaria y placentera, y enseñarlo debe tener esto en cuenta".

Como los alumnos de la Maestra F, los niños de este grupo tienen libros de recreación en sus mochilas o sobre sus pupitres, que leen al recreo y al término de cada tarea. Rafael Orellana (s/f), al definir la lectura independiente lo hace como una actividad que necesita cierto nivel de autonomía, ya que se realiza de modo silencioso y "con el mínimo apoyo del docente".

\section{Leer, ¿una cuestión de espacio?}

Partiendo de la idea de Lerner (1995) de que propiciar espacios de lectura es "abrir para todos las puertas de los mundos posibles", analizamos qué espacios se generaban en las aulas visitadas. A través de ellos es posible el acercamiento a las diversas concepciones de lectura que poseen los maestros y su valoración de la lectura placentera. 
Los salones de clase de las Maestras A y B eran muy espaciosos. Poseían tres bibliotecas cerradas, dos de las cuales servían como muebles sobre los que se dejaban los cascos de los alumnos, el globo terráqueo y el papelógrafo. Una de ellas, a su vez separaba la zona de trabajo de la de los gabinetes higiénicos. Las mesas auxiliares del primer salón se destinaban a las Ciencias Naturales, mientras que la cartelería mostraba temas de Lenguaje, Matemática, Historia y Ciencias Naturales. La Maestra B había dispuesto al frente sobre la derecha, el rincón de lectura, un lugar acogedor y lleno de colorido, con tres sectores bien diferenciados: la pared, el banco de plaza de pequeñas dimensiones y el lugar de los libros. En la pared podían verse tres amplios sobres de color con las leyendas "Grandes oportunidades", "Recomendamos", "Nos recomendaron", en carteles escritos por los niños. El material de lectura estaba ordenado en grandes cajas forradas con papeles de colores y etiquetadas: "Libros", "Diarios", "Revistas".

A su vez funcionaban como bibliotecas circulantes de donde los alumnos seleccionaban lecturas para llevarse a sus casas.

Paralelamente, la docente llevaba una carpeta de producciones externas que se iba acrecentando con los textos producidos por los propios niños y mecanografiados por ella, que era enviada a las familias para que pudieran reconocer los avances de los pequeños.

La Maestra $\mathrm{C}$ trabajaba en un salón muy angosto. En la única pared disponible había mensajes relacionados con la lectura además de la cartelería de Historia, Geografía, Matemática y Lenguaje. Aunque las dos bibliotecas estaban cerradas con llave, la correspondiente al grupo estaba a disposición de los niños, que solicitaban libros para leer en la clase o para llevar a sus casas. Entre los dos muebles, una mesa cumplía la función de biblioteca abierta, con libros, diarios y revistas a los que se podía acceder sin pedir autorización. Los alumnos tenían sus propios libros-cuentos y novelas-en sus mochilas o sobre el pupitre, además de llevar otros para prestarse entre sí. A la hora de trabajar, la maestra optó por textos breves fotocopiados que los niños pegaban en sus cuadernos, pero para la lectura placentera tomó una novela. Sus propias lecturas modélicas en clase eran de novelas de autores reconocidos y artículos periodísticos.

Las dimensiones del salón de clase de la Maestra D eran enormes. Al fondo había dos bibliotecas cerradas con libros de estudio inutilizables. En el frente se ubicaba el rincón de lectura, verdadero corazón de la clase. En la entrevista contó su historia de la siguiente manera: "Se ha buscado implementar los rincones de lectura, las zonas de lectura. En un tiempo no se podía hablar de rincones, ahora se vuelve a usar la palabra, y se trata de leer todo lo que los chiquilines traigan de la casa, lo que ellos quieran leer, no lo que les impongamos... Pero lo que yo hice fue, en la parte de adelante, había un rincón como una biblioteca abierta, con estantes de madera y almohadones que fueron aportados por ellos. Todo esto a raíz del proyecto de lectura de la escuela, para incentivar la lectura en la clase. Y como había problemas de conducta cuando yo me hice cargo del grupo, cuando ellos terminaban sus tareas tenían en el lado de la lectura un espacio. Sin tener que decirme nada a mí agarraban un almohadón y se sentaban a leer. Incluso tenían el logo del proyecto que era como una señal de tránsito, que también la habían hecho ellos y que después, con el tiempo se fue rompiendo. Esa zona estaba para eso. El espacio lo fueron alimentando ellos con revistas que traían, incluso libros de cuentos que traían por el año y a fin de año se los llevaban para la casa. Estaban bajo el polvillo de la tiza, que era un trabajo limpiarlos. Había equipos encargados de limpiarlos cada día".

La descripción da cuenta de los escasos recursos con que cuentan algunas escuelas, pero también de la búsqueda de alternativas, del compromiso de la docente con su profesión y con sus alumnos, y el valor de estos espacios, -implementados con los mínimos requerimientos-, en la formación de lectores. Tal vez lo más importante sea que en ellos, el niño ya no deba leer para demostrar cuánto entendió, sino para sí mismo, fomentándose entonces la formación 
de criterios personales de selección y respetándose también el derecho a no leer. Desde el instante en que ingresamos al salón de clase de la Maestra E pudimos notar las dificultades a las que se enfrentaba cada día. Se trataba de un salón más largo que ancho, con el escritorio ubicado sobre la pared del fondo, dividiendo el grupo en dos sectores a derecha e izquierda. Las dos bibliotecas, enfrentadas, una al frente y otra al fondo, provocaban una sensación de ahogo que se sumaba a un pizarrón móvil que, para ser utilizado, debía colocarse ocultando la puerta. Y no había forma de evitarlo ya que el pizarrón central es muy angosto. La maestra trabajó con dos breves textos fotocopiados y otro copiado en el pizarrón y dos esquemas realizados de manera algo errática que los alumnos definieron como "una guerra de palabras".

Por último, el aula donde trabajaba la Maestra $\mathrm{F}$ tenía un amplio espacio al frente, poco aprovechable ya que en un ángulo se ubicaba una biblioteca cerrada y el escritorio y en el otro estaba la puerta de entrada. En el fondo del salón se encontraba el segundo mueble, también cerrado. No pudimos apreciar movimientos en torno a ellos, aunque los chicos hacían uso de la biblioteca escolar, portaban uno o más libros-novelas o colecciones de cuentos- a los que recurrían cada vez que las tareas de clase se los permitían y comentaban, recomendaban y prestaban entre sí. La maestra recurrió a textos fotocopiados que eran pegados en los cuadernos para trabajar en la clase, aunque la lectura placentera se realizaba de una novela, un capítulo por semana. También sus lecturas modélicas, mientras los alumnos realizaban sus labores, eran de novelistas contemporáneos.

Al hablar de los espacios de lectura, resumimos, estamos refiriéndonos a lugar físico que se instala en el aula y al uso que del mismo se hace. Pero también se refiere a los tiempos que los Docentes conceden a sus alumnos en el horario de clase para que puedan desarrollar ese hábito, los que les permiten convertirse en los viajeros de Michel de Certeau (citado por Bavosi, 2008) que, "circulan por tierras ajenas, nómadas dedicados a la caza furtiva en campos que no han escrito". Y para ello es necesario aislarse de lo que los rodea, para fundirse en uno con el libro.

\section{Al otro lado del río}

Una maestra encuestada se cuestionaba cuánto de la lectura transaccional sabían los docentes, no en la teoría sino en las prácticas.

En nuestras observaciones pudimos detenernos en esta concepción contrastando las prácticas de dos maestras, ambas apasionadas por la lectura, comprometidas con la formación de lectores y llevando adelante un proyecto de lectura internivel, secuenciado a lo largo de dos años, con la ayuda de expertos. En ambas clases se propiciaban los tiempos de lectura placentera individual y se asumían posturas similares frente a ellos. Un día a la semana, pactado con anterioridad con sus alumnos, leían un capítulo de una novela elegida entre todos o un texto completo cuando se trataba de una colección de cuentos.

La primera visita a la Maestra C coincidió con día de lectura placentera. Los niños se mostraban muy ansiosos por realizar las actividades que se iban proponiendo. Al final se produjo el siguiente diálogo:

M: Bueno. Ahora la pegan en el cuaderno. Tengan cuidado con la cascola, que esté bien puesto el taponcito, que ya hubo un accidente acá.

A: Maestra, ¿vas a leer?

M: No sé si me va a dar el tiempo para leer todo el capítulo. 
La transcripción continúa. La maestra comienza a leer un capítulo de "Juanita Julepe y el río de los zombis" de Roy Berocay. La clase sigue en desorden pero de a poco van haciendo silencio. Algunos niños conversan, otros recortan, dos están con sus calculadoras, una niña busca en su propio libro la página que la maestra está leyendo. Cuando termina la lectura los niños hacen aportes sobre la misma, el título, etc. Hasta quienes no parecían atentos comentaron el texto. Luego, antes de terminar la clase, la maestra anotó en el pizarrón la tarea domiciliaria, los alumnos copiaron y consultaron sus dudas.

La Maestra F también estaba leyendo un libro de Berocay, "El abuelo más loco del mundo". En la tercera observación de clase sucedió lo siguiente:

M: Vamos a poner la fecha. Hoy es miércoles 19. ¿Vamos a terminar este libro si les parece mientras esperamos al resto de los niños? ¿Se acuerdan de lo que pasaba? (Los alumnos reconstruyeron la historia).

La maestra comienza la lectura del segundo capítulo, mientras algunos niños están muy atentos, otros arreglan sus útiles. Van llegando los rezagados y se ubican en sus lugares.

M: Hasta aquí leemos hoy.

A: ¡Qué cortitos son los capítulos!

M: Bueno, tenemos que poner la fecha, "Tomamos la palabra", "Leímos 'El abuelo más loco del mundo'". Ya leí, ya los desperté, ahora les toca leer a ustedes.

La clase continuó su rumbo. Algo similar había sucedido en la observación anterior al pasar del comentario de "Hombre quieto" abruptamente a un tema de geometría:

M: Bueno, pegan la hojita. (Les da tiempo para que lo hagan). ¿Se acuerdan de que hemos hecho programas de construcción?

Al repasar las concepciones sobre la lectura nos deteníamos en la postura de Rosenblatt. Ésta, al centrar su atención en el lector determinaba dos tipos de actitud frente al texto. En los casos que acabamos de transcribir, las docentes se instalan en la estética, ya que se trata de lectura placentera. El lector (hablamos de lector "pasivo", por cuanto el otro -la maestra- le está prestando la voz y su competencia lectora) no se preocupa por lo que debe retener para después; sabe que no tiene que contestar preguntas o demostrar que estaba atento. Puede, entonces, construir el sentido desde el sonido, el ritmo, las asociaciones y las vivencias de los personajes. También es pertinente la idea de Mijail Bajtin de que "todo texto remite a otro texto", dependiendo de la experiencia lectora de cada uno. Muchas de las clases observadas dejaban entrever esa experiencia de los alumnos.

La Maestra C permitió el proceso transaccional dando tiempo a sus niños para que comentaran el capítulo leído, su relación con el título, las emociones que les había provocado, las risas, para luego pasar a anotar y explicar la consigna de la tarea externa. Ese tiempo y ese espacio generados por ella son germinales, ya que pueden convertirse en motivadores profundos de la lectura o la relectura. Es el tiempo de reflexión que permite al lector reencontrarse tras el impacto del texto, la música al final de la película que devuelve al espectador a su realidad luego de haber sido transportado a otros mundos, la canción principal de "Diarios de motocicleta", que emerge recién y suavemente cuando aparecen los créditos, resumiendo la historia y resignificando una escena que define el cambio decisivo del personaje. De ahí el título de este apartado. 
En la Maestra F irrumpió el curriculum oculto, expresión acuñada por Jackson (1992) para crear una categoría que describe los procesos de socialización no intencionados, los hábitos que generan prácticas individuales y sociales que están más allá de la conciencia de alumnos y profesores; en este caso, concepciones sobre la lectura que no son reconocidos y contradicen su propio proyecto de lectura. Al decir "Bueno, pegan la hojita", en la segunda clase, inconscientemente cerró un segmento de la clase, dando la sensación de que lo verdaderamente importante venía recién a partir de ese momento.

En cuanto a la primera transcripción (perteneciente a la tercera observación), la práctica vuelve a oponerse a los objetivos declarados en el proyecto de lectura, entre ellos al que se refiere a "buscar la adquisición y la consolidación del hábito lector". En primer lugar, el comentario de uno de los niños tras la lectura ("¡Qué cortitos son los capítulos!") pudo dar lugar a la lectura de otro capítulo, pues apenas sobrepasaban una carilla cada uno. Como las palabras dicen más que las intenciones, el sentido del placer desaparece cuando la maestra continúa "Bueno, tenemos que...". Claramente se percibe la rutinización que pone en riesgo el placer buscado. La actividad se ha estereotipado, convirtiéndose en un sistema de premios a los que llegaron en hora: "¿Vamos a terminar este libro si les parece mientras esperamos al resto de los niños?", y castigo a los rezagados. El uso de las expresiones "destacadas" denota la rutinización de la tarea, lo que se confirma con el cierre que realizó del segmento: "Ya leí, ya los desperté, ahora les toca leer a ustedes". En la entrevista informal que tuvimos después y que no fue debidamente registrada, la docente escuchó la grabación y notó inmediatamente que había hecho "justo todo lo que no quiero hacer".

Esa brecha entre el discurso y las prácticas es la que debe ser analizada. Santos Guerra (2000) señala que la función de la escuela es enseñar, pero para ello tiene que aprender, porque la enseñanza es una función compleja y problemática. Este aprendizaje se logra con docentes capaces de generar teoría partiendo de la observación y del análisis de las propias prácticas. Primero deben aprender a hacerlo; luego invertir más tiempo en la enseñanza: tiempo para preparación de la clase, tiempo en la clase, tiempo para la autoevaluación. Los dos primeros están institucionalizados; el tercero está aún entre las deudas que tiene la escuela consigo misma.

Pero las contradicciones entre el discurso y la práctica aparecieron también en otros docentes. La Maestra E señaló en su encuesta que dedicaba de cuarenta y cinco a sesenta minutos diarios a la enseñanza o fomento de la lectura. Sin embargo, en ninguna de las visitas realizadas a su clase pudimos ver de qué manera lo hacía. La mayoría de los encuestados cree que sus prácticas de enseñanza favorecen la formación de lectores. Pero mientras algunos le dedican diez horas semanales (casi siempre en $1^{\circ}$ año), otros lo hacen "dos o tres veces por semana".

Al ser entrevistada, la Maestra D señaló: "Leo poco, muy poco. No leo por placer. Eso que yo trato de inculcarle a mis gurises, yo no lo hago.[...] No leo muy seguido, lo hago más con mis hijos. Soy más del color y de la imagen. [...] No me interesan los libros para adultos, pero los de los niños me atrapan".

Las "campanas de alerta" que menciona Perkins (2001) aludiendo al poema de Poe están siendo escuchadas. La escuela tiene que repensarse para empezar a acortar distancias.

\section{Domesticar al monstruo: las TIC}

A mediados de 2009 llegó a la ciudad el Plan Ceibal. El paisaje cambió. Los edificios escolares se convirtieron en centro de reunión de enjambres de niños quienes, sentados en las veredas, afirmados en las paredes de las escuelas o de casas cercanas, manipulaban con satisfacción esas pequeñas laptops blancas y verdes apoyadas en sus rodillas o en el suelo. Lo 
que creímos que sería una moda pasajera, producto de la novedad de la computadora portátil propia, parece haberse fusionado con la identidad local. Casi dos años después la situación se mantiene incambiada.

Sin embargo, no todo ha sido satisfacción desde que OLPC desembarcó en nuestro país. El Plan Ceibal tiene sus defensores y sus detractores. No es novedad que las TIC no han encontrado hasta el momento cabida masiva en la escuela. Una gran cantidad de docentes no ha podido hacer suyo el desafío de integrar estas tecnologías con el objetivo de enriquecer los ambientes de aprendizaje que puede generar en sus aulas. Para algunos provoca aprensión el "descontrol" de que los alumnos "hagan cualquier cosa" o simplemente jueguen con las computadoras. Otros se animan a manifestar su incompetencia o su temor a verse en desventaja ante los niños. Citando a Burbules "ya no tienen el rol de dueños monopólicos o custodios del conocimiento". Y si bien todos están de acuerdo en que es necesario que los chicos se preparen para el mundo hiperinformado en que están inmersos, y que la escuela es el lugar natural para aprender a relacionar la información nueva con sus esquemas cognitivos previos, no todos se sienten preparados para ayudarlos en esa aventura de aprender a aprender.

Quisimos conocer la postura de los docentes frente a las TIC como instrumentos para la enseñanza de la lectura y saber si las habían incorporado al trabajo de clase. De la encuesta realizada se desprende que la mayoría utiliza la computadora para la búsqueda de información en Internet. Algunos maestros realizan otro tipo de actividades relacionadas con lenguaje (búsqueda de palabras con dificultades ortográficas, trabajo con tipologías textuales, producción de textos, lectura de cuentos) así como la creación de un "blog". Los programas más utilizados son el de escritura y el de "la carita que les habla". Una minoría, en cambio, manifiesta que no la ha incorporado a sus prácticas, con motivos tales como "porque los alumnos se ven motivados por otros aspectos como los juegos", "por desconocimiento y desinterés. El libro u otro texto impreso es más cálido", "no sabemos usar la XO en forma correcta" o "incorporé la XO pero sigo defendiendo los libros".

Con respecto a su uso para la enseñanza específica de la lectura, una maestra responde "las computadoras no son instrumentos adecuados ni imprescindibles para la enseñanza de la lectura, no son condición necesaria para la enseñanza de la lectura ni para la formación de lectores. Preferiría buenos textos para todos los niños". Detrás de esas palabras está el temor a reconocer que los adultos, y en particular los docentes, también tenemos que aprender a aprender. Otra maestra, comprometida con la enseñanza de la lectura placentera, pudo expresar sus miedos de manera más explícita: "... yo le cerré la puerta porque a mí esa cosa me supera y porque venía a mil tratando de ganarle, tratando de llegar antes con la lectura, antes de que llegara la máquina. Ahora lo que tengo que ver es cómo puedo hacer para meter la máquina y meter la lectura. Ésa era la idea que tenía, llega la máquina y se nos va a terminar todo. El tema es que nosotros venimos haciendo un trabajo para hacer que el niño se prenda de la lectura, y la máquina nos viene a hacer la competencia. Y me parece que nosotros no estamos preparados como para meter la máquina en la lectura, como para juntar las dos cosas. Ése va a ser mi desafío del año próximo. Porque ahora la máquina está, todo el mundo la tiene, y hay que buscar la forma de que todo el mundo la use". Toda la cita es riquísima. Los textos destacados sólo señalan algunos elementos fácilmente reconocibles: en principio el miedo a lo desconocido cuando se refiere a la laptop como "esa cosa", y la reiteración del sustantivo "máquina" (seis veces). Lo desconocido es, además, apocalíptico: "se nos va a terminar todo". Aparece también la idea de competencia, una vez de manera explícita y otra implícita "tratando de ganarle". Y, perdida la lucha, la resignación, que se traduce en el cambio de tiempo verbal de pasado a presente y la reiteración del adverbio temporal "ahora", que se asocia al acatamiento: "tengo que ver", "hay que buscar la forma". A continuación relata en 
qué situaciones la emplea: trabajar con canciones, búsqueda de información, pero sin tener claro cómo, sin las orientaciones mínimas. Nadie le dijo que la primera búsqueda tenía que hacerla ella en su casa, o en qué consistía su nuevo rol: "... el otro día trabajamos con Páez Vilaró y lo que consiguieron no me convenció mucho y ya lo dejamos".

La implantación del Programa Ceibal ha distado mucho de ser buena. Los tiempos en la política no son los de la educación, y la urgencia porque cada niño tuviera su computadora provocó situaciones algo incómodas. Muchos maestros se vieron desbordados. Algunos aún no habían incursionado en el uso de esta tecnología y de pronto se vieron teniendo que enseñar a usarla a un grupo entero de niños que, en muchos casos, ya la manejaban. Faltó preparación y conocimiento de la herramienta, que no se logra con dos charlas multitudinarias y un manual casi inaccesible sino con práctica, ensayo y error, y la presencia de especialistas junto a los maestros para evacuar todas las dudas que surjan.

Ahora está comenzando a transitarse el lento y doloroso proceso en el que cada actor debe reconocer sus limitaciones y aceptar la ayuda de sus pares para transformarse en la "comunidad de aprendices" que establecía Simonds. Y tendrá que ser así, porque desde 2008 se realizan, en cada ciudad del país, muestras de prácticas exitosas de enseñanza mediadas por tecnologías, pero los planes de Formación Docente no contemplan aún el uso de las "Ceibalitas". Los estudiantes tienen en su plan de estudios dos horas de Informática en el tercer año de los cuatro que dura la carrera, pero el curso no está dirigido a su aplicación en la enseñanza, por lo que son los docentes quienes deciden la inclusión del manejo de las laptops, sus programas (que son muchos e interesantes) y su posibilidad de actualización constante desde el Portal Ceibal, así como el tiempo que dedicarán a esta parte esencial para las nuevas generaciones de maestros.

En 2010 se creó el cargo de Maestro Dinamizador del Plan Ceibal, uno en cada turno en todas las escuelas, que son los encargados de asistir a inspectores, directores, maestros de aula y de Informática en el uso educativo de las XO. Además organizan y desarrollan reuniones y espacios de intercambio de experiencias, producción de materiales de difusión y otras actividades relacionadas con el Plan. Asimismo, los estudiantes del último año de Magisterio empezaron a recibir sus propias $\mathrm{XO}$, y con ellas, el desafío y la responsabilidad de adquirir las habilidades necesarias para convertirse en "Maestros del Nuevo Siglo".

\section{La hidra desmitificada}

La Maestra B tenía, al momento de la investigación, treinta y dos años de trabajo y estaba a cargo de un grupo de Primer año. En 2003, mucho antes de la llegada de las XO, ella ya llevaba su propia laptop al aula y la dejaba abierta sobre el escritorio conviviendo con las otras herramientas de uso cotidiano. Para llegar a este momento debió prepararse, tomó algunas clases aunque se considera autodidacta. También había logrado tener una computadora en el salón y enseñaba a sus alumnos sus partes: el monitor, el teclado, la torre, el mouse, desde el primer día de clase. Allí iban reconociendo las letras, para lo que se sentaban todos en el piso en torno a la máquina. La maestra seleccionaba la aplicación Microsoft Word y un tamaño de letra grande. El entusiasmo de los niños era tal que se esmeraban en las tareas del cuaderno para utilizar los minutos libres en la computadora. Primero producían listas de palabras, luego enunciados y, poco después, breves producciones de texto. Cuando comenzaron a escribir pequeños cuentos, ella los llevaba a su casa, los imprimía y formaba una "carpeta viajera" para que los padres pudieran ver lo que los niños hacían. Esto fomentó la producción externa, que ya venía impresa de la casa. 
"Cuando dijeron que venía una computadora para cada uno de ellos, era lo ideal. Yo pedí muchas veces una sala de informática en la escuela, un salón con una sala de informática. Porque con una sola computadora yo podía hacer algo, pero no lo que ellos requerían y lo que yo consideraba que quería hacer", relata.

La incorporación de las XO fue natural para esta maestra. Sus alumnos aprenden primero sus partes, cómo tratarla y todos sus programas de manera muy espontánea. Luego van eligiendo sus programas favoritos. Uno de ellos es el "de hablar" (sintetizador de voz): escriben una palabra, la computadora la "dice" y los niños comprueban si la escribieron correctamente o no. Y del error van aprendiendo. También el programa de escribir Write ${ }^{\circledR}$ es valioso ya que saben que la marca en rojo les indica un error ortográfico y la verde el gramatical. Pero, a diferencia de "Word", no tiene corrector ortográfico. Ahí empieza la lucha por reparar el error, y se esfuerzan al máximo por hacerlo sin intervención de la maestra.

En poco tiempo logran producciones de cierta complejidad. Por ejemplo, llevan una mascota a clase, la fotografían, la describen oralmente entre todos alentados por la maestra para que empleen adjetivos, comparaciones y enunciados completos y no palabras sueltas. Luego encienden sus computadoras, ingresan al programa adecuado, seleccionan el tipo y tamaño de letra que más les gusta, producen un texto descriptivo y por último insertan las fotos.

Con respecto a la lectura, la maestra refiere un avance notorio en quince días desde la entrega de las computadoras -lo que sucede a mediados de mayo aproximadamente-. "La agilidad en el teclado les hace esmerarse muchísimo más en saber las letras", dice. El incentivo es la posibilidad de entrar a Internet donde buscan poemas y canciones que memorizan, y para ello deben practicar lectura. También descubren un mundo de información que amplía o modifica los temas tratados en la clase. A esto se suma la solidaridad que se obtiene trabajando en equipo buscando en la red. Si uno no puede llegar a la información o a la página sugerida porque escribió mal la palabra en el buscador, otro se la corrige, la borra y la escribe bien, y es una ayuda que usando otro tipo de herramientas no se ve.

Pero no sólo ha incorporado el uso de las computadoras a sus prácticas. También utiliza el teléfono celular. La primera tarea de cada día consiste en escribir dos o tres enunciados, uno de ellos lo producen como mensaje de texto que se envían los niños entre sí. De esa forma, mientras ejercitan escritura y lectura, la maestra los va preparando para una adecuada inserción en el mundo.

Señalamos antes los errores de implementación del Plan Ceibal. Debemos agregar ahora que exige a los maestros compromiso para revertir sus debilidades. Cerramos el apartado con las reflexiones de la maestra experta:

"Pienso que no tenemos que cerrarnos, creo que ellos están en la edad en que tienen el mayor poder de aprendizaje. [...]... es una apertura al mundo impresionante, que el niño con un libro no lo alcanzaba. Para mí el libro es importante, y que el niño tenga esa familiaridad con el libro nunca se va a dejar escapar, pero con la computadora les abrimos la puerta al mundo a los chicos". 


\section{La historia sin fin}

En un mundo cambiante, la enseñanza no puede quedar afuera de los avances. Quienes hemos elegido la carrera docente sabemos que se trata de una profesión que da pequeñas grandes satisfacciones personales, pero también que exige actualización constante. Mientras se desarrollaba esta investigación se produjeron dos hechos decisivos en Educación Primaria: la incorporación de la XO, y la discusión y posterior aplicación del nuevo Plan de Enseñanza que modificaba la visión del que estaba vigente hasta el momento, y que ordenaba las sugerencias esparcidas en diversas circulares.

En la encuesta los maestros mencionaron la hasta ese entonces Propuesta Educativa. Dos de ellos expresaron estar "a la espera de los cambios" ya que "el nuevo programa da relevancia a la lectura". Otro decía: "El nuevo programa presta mayor atención a la lectura y esto puede llevar a un cambio de actitud de parte de los docentes al contar con más tiempo para dedicar a esta actividad".

La Maestra D opinó en la entrevista: "¡Y qué te parece, no hay preparación previa! Para mí es un desafío porque antes nos quedábamos en lectura, escritura, oralidad y chau. Nunca la literatura. Lo veo elevado pero a la vez está buena la propuesta. Que el chiquilín de las clases grandes pueda acercarse a una novela, a mí me parece fascinante. [...] Y la literatura desde la parte de lo artístico y de la sensibilización, la lectura por placer. Lo que veo es que no tenemos material para trabajar estas cosas. La maestra que no tiene alguien para consultar no sabe mucho cómo trabajarlo".

Tampoco hubo instancias de preparación. Cada maestro, además de planificar su trabajo, debió volver a estudiar para poder enseñar, lo que revela las concepciones subyacentes en la mayoría de ellos. Desde el discurso, los docentes deben enseñar a aprender. En la práctica siguen enseñando contenidos. Para poder llevar a cabo lo que dicen, resulta fundamental que reflexionen críticamente acerca de sus prácticas de enseñanza.

\section{Conclusiones}

Iniciamos nuestro trabajo mencionando la postura generalizada de cuestionar la tarea de la escuela en la formación de niños lectores. Creíamos ver una brecha entre la Educación Preescolar e Inicial y la Educación Común y así lo consignamos. Pero a medida que íbamos conociendo el "Estado del Arte" fuimos descubriendo que se trataba de una situación mucho más compleja que coexistía con nuestra idea inicial. La reforma del Plan de Educación Inicial y Primaria tendiente a acortar esa grieta nos daba la razón, y la convivencia de diversas concepciones de la educación y la enseñanza de la lectura habilitaban nuevos cuestionamientos.

Este trabajo nos posibilitó conocer de cerca las contradicciones, las concepciones divergentes, las debilidades, los miedos e inseguridades que rodean a los maestros. Pero no era esto lo que nos convocaba sino sus buenas prácticas en torno a la formación de lectores. Y las encontramos, a pesar de los desafíos que enfrentan cada día y de la soledad en que deben trabajar. Seguramente no hay aquí grandes descubrimientos, al menos para quienes realizan estas prácticas cada día. Para nosotros significó una gran apertura, un cambio de mirada, una respuesta a la pregunta de la Introducción: "¿Qué es lo que les enseñan a los chiquilines en la escuela, que no saben nada?". Y es que "No tenemos idea de cuánto".

La escuela tiene maestros que actualizan sus conocimientos, que con sentido crítico analizan sus prácticas y que reconocen que muchas veces están alejadas de las teorías, leídas pero no aprehendidas. 
Con respecto a la lectura pudimos observar la coexistencia de concepciones modernas con otras que, en la teoría, y a veces en el discurso, hace ya tiempo fueron superadas. Desde las nuevas concepciones, el alumno se vuelve el centro de la enseñanza y también de la lectura, concepciones que lo convierten en constructor del sentido del texto, porque en primer lugar, se les explica el objetivo que se busca con cada actividad.

Se atiende la lectura como objetivo en sí mismo, en particular en el primer nivel, y como instrumento de conocimiento en todos los niveles, de la misma manera en que tiene su espacio la lectura recreativa, provocadora del gozo estético. Los maestros realizan actividades, siempre variadas, que permiten al alumno reconocer y verbalizar las estrategias empleadas para comprender los textos y las posturas que se pueden tomar ante ellos de acuerdo a su tipología. Así el niño construye su propio aprendizaje desde sus conocimientos previos, los cuestionamientos que provocan las lecturas y el trabajo en equipo; un aprendizaje reflexivo logrado gracias a la socialización del conocimiento. Actividades de ese tipo le permiten preguntar cuando no ha comprendido algo, capacitarse para establecer analogías entre los temas propuestos y sus propios saberes y lecturas, ejemplificar, aplicar y explicar. La preocupación por formar lectores competentes lleva a los maestros a abrir las puertas de las aulas para que ingrese el mundo de los alumnos, procurando dar fin así al desmenbramiento de la escuela. De tal modo, se vuelven importantes las noticias locales y mundiales, todo es tema de discusión, todo sirve para aprender relacionando saberes.

Las aulas se han convertido en espacios más y mejor adecuados a quienes pasan varias horas en ellas. Los niños salen de sus asientos para discutir la resolución de un problema con compañeros más alejados, se acercan a las carteleras en busca de alguna información que necesitan, revisan los mapas para sacarse alguna duda, leen en sus ratos libres diversos textos que llevan consigo o que encuentran en la clase, comparten opiniones sobre alguno de ellos, los intercambian, siempre ante la mirada atenta de los maestros que los dejan actuar libremente bajo reglas de convivencia pactadas con anticipación.

La lectura recreativa tiene su lugar en la planificación, siempre cuidadosa, de la clase; aunque también se da lugar a los emergentes, a las dudas de los alumnos, a sus propuestas, compartiendo con ellos la organización de los tiempos de recreación. Esos espacios de lectura son muy significativos ya que los alumnos deciden qué, cuándo y dónde hacerlo, se fomenta la creación de bibliotecas de aula o circulantes con los aportes de cada uno, y también se respeta el derecho a no leer. La creación de rincones de lectura propone un espacio acogedor, lleno de colores, rodeado de libros, asientos o almohadones y lugares para escribir sus comentarios sobre los textos leídos, compartiendo emociones y descubrimientos con otros compañeros.

En los casos más osados, los maestros se muestran a sí mismos como modelos lectores, utilizando los "ratitos libres" para realizar sus propias lecturas placenteras, promoviendo así la independencia de sus alumnos. Éstos, viéndolos concentrados en sus lecturas, buscan entre sus saberes la manera de resolver sus dudas, y sólo como último recurso consultan a los docentes. Por su parte, los docentes están atentos a lo que pasa en la clase y dispuestos a aclarar todas las dificultades que surjan, pero insisten en la voluntad que los niños ponen para aplicar los conocimientos ya adquiridos. 
Cuando se trata de la enseñanza de la lectura como objeto en sí mismo se incorpora el juego: la búsqueda y memorización de chistes, colmos, destrabalenguas, poemas y canciones permiten la ejercitación de la lectura de manera más amena. De igual modo sucede con la presentación de cuentos como rompecabezas que deben armar buscando el sentido de las historias. El aula expandida -leer cuentos a niños de otras clases- les ofrece la satisfacción de compartir con el resto de la Escuela sus avances en lectura; la lectura en voz alta como opción y no por imposición del docente.

También el maestro lee a sus alumnos textos recreativos de manera modélica, a la vez que presta su voz para el disfrute pleno de la riqueza de aquéllos, que sólo alcanza el lector competente.

En el trabajo con las computadoras, los maestros van cambiando su rol sin temor a la obsolescencia. Se asumen como guías en la construcción del conocimiento puesto que, particularmente en el uso de Internet, los alumnos manejan la tecnología, pero deben aprender a ser críticos para seleccionar la información más valiosa. Los hipertextos, que son recomendables para aprender a leer, también deben saber leerse. Para hacerlo eficazmente necesitan quien les enseñe. Quienes ingresan al ámbito escolar pueden tener experiencia con la computadora a través de los juegos, pero el deseo de escribir, de buscar chistes o letras de canciones los impulsa a reconocer las letras más rápidamente, también como un juego.

Todo esto sin perder de vista la afectividad. Los maestros se sientan en el suelo junto a ellos, ríen y cantan con ellos, se preocupan por ellos, acarician sus cabezas o prestan sus piernas para que los niños afirmen allí sus cuadernos cuando están desbordados por propuestas que no pueden resolver, les dan confianza en sí mismos y los alientan, trabajando siempre sobre la imagen que tienen de sí mismos para que realicen aprendizajes significativos. Tales son las prácticas docentes que favorecen la formación de niños lectores. Hay mucho que corregir pero creemos que se está transitando por el camino correcto.

\section{Bibliografía}

ANEP. 1986. Programa de escuelas urbanas. Montevideo: ANEP.

ANEP. 2008. B. Montevideo: ANEP.

Ausubel, D. 1976. Psicología educativa. Un punto de vista cognoscitivo. México: Trillas.

Bavosi, A. M. 2008. Leer o no leer: ¿A quién le importa. [online], [citado 15 febrero 2008]. Disponible en Internet: <http://www.laondadigital.com/laonda/laonda/201-300/285/A1.htm>

Braslavsky, B. 2008. Enseñar a entender lo que se lee. La alfabetización en la familia y en la escuela. Buenos Aires: F.C.E.

Bravo Valdivieso, L. 2003. Alfabetización inicial y aprendizaje de la lectura, presentado en Foro Educativo 2003. PU Católica. Facultad de Educación, Santiago de Chile. Accedido el 23 de febrero, 2008, desde http://www.psicopedagogia.com/articulos/?articulo=442

Bruner, J.1984. Desarrollo cognitivo y educación. Madrid: Morata.

Bruner, J. 1997. La educación: puerta de la cultura. Madrid: Visor.

Burbules, N.; Callister, T. 2001. Riesgos y promesas de las nuevas tecnologías de la información. España: Granica. 
Cabello, R. "Yo con la computadora no tengo nada que ver". Sobre usos posibles, usos mentados y no usos. En: Cabello, R. (com.) 2006. "Yo con la computadora no tengo nada que ver". Un estudio de las relaciones entre los maestros y las tecnologías informáticas en la enseñanza. Buenos Aires: Prometeo Libros.

Castillo Burgos, A. 2002. ¿Quién abrirá los libros? La escasez de lectores genera la responsabilidad de formar lectores. En: Quehacer editorial, año 1, (1).

Castrillón, S. 1989. ¿Estamos formando lectores? En: Libros de México, (16), p. 40.

Coiçaud, S. 2008. La investigación cualitativa en las Ciencias Sociales. Material preparado para la Maestría en Procesos Educativos Mediados por Tecnologías. Universidad Nacional de Córdoba.

Coll, C. 2005. Lectura y alfabetismo en la sociedad de la información. En: UOC Papers [online] No 1 UOC. Accedido el 24 de marzo, 2011, desde http://www.uoc.edu/uocpapers/1/dt/ esp/coll.pdf

\section{COMISIÓN DE EDUCACIÓN, 2007. CEIBAL. Proyecto Pedagógico. Montevideo, ANEP.}

Cook, T. D. y Reichardt, Ch. S. 1995. Métodos cualitativos y cuantitativos en la investigación evaluativa. $2^{\circ}$ ed. Madrid: Morata.

Cullen, C. 2005. Crítica de las razones de educar. Temas de filosofía de la educación. Buenos Aires: Paidós.

Czarny, M. 2000. La escuela en Internet. Internet en la escuela. Propuestas didácticas para docentes no informatizados. Rosario: Homo Sapiens.

Davini, M. C. 2005. La formación docente en cuestión: política y pedagogía. Buenos Aires: Paidós.

Dubois, M. E. 1995. El proceso de lectura. De la teoría a la práctica. Buenos Aires: Aique.

Fenstermacher, G. Tres aspectos de la filosofía de la investigación sobre la enseñanza. En: Wittrock, M. 1989. La investigación de la enseñanza. Enfoques, teorías y métodos I. México: Paidós, pp. 149-179.

Ferreiro, E. 2005. Pasado y presente de los verbos leer y escribir. Buenos Aires: F.C.E.

Ferreiro, E. 2008. Entrevista de Myriam Southwell. En Revista de la Coordinación General de Extensión Universitaria, № 2. [online] Universidad de Colima. Accedido: 2 de febrero 2011. Disponible en: <hip://www.ucol.mx/extension/revista/presentacion/portadas/marzo/ REVISTA\%20MARZO.pdf>

Fraca, L. 1993. Estudio internacional sobre el desempeño en la lectura. En: Revista Lectura y vida, 14 (1), pp. 5-12.

Géliga Vargas, J. Acceder, cruzar, nivelar: Disyuntivas escolares ante la brecha digital. En: Cabello, R. (comp.). 2006. "Yo con la computadora no tengo nada que ver". Un estudio de las relaciones entre los maestros y las tecnologías informáticas en la enseñanza. Buenos Aires: Prometeo Libros, pp. 41-87.

Glaser, B.; Strauss, A. 1967. The discovery of grounded theory: Strategies for qualitative research. Chicago: Aldine.

Goetz, J. y Le Compte, M.D. 1998. Etnografía y diseño cualitativo en investigación educativa. Madrid: Morata.

Goodman, K. El proceso de lectura: consideraciones a través de las lenguas y el desarrollo. En: Ferreiro, E. y Gómez Palacio, M. 1982. Nuevas perspectivas sobre los procesos de lectura y escritura. Buenos Aires: Siglo XXI, pp. 13-28. 
Hébrard, J. 2000. El aprendizaje de la lectura en la escuela: discusiones y nuevas perspectivas. [online]. [citado 22 de diciembre 2008]. Disponible en Internet: <http://www.r020.com.ar/ extradocs/lectura.pdf>

INSPECCIÓN NACIONAL DE EDUCACIÓN COMÚN, 2006. Circular Nº 8. Montevideo, ANEP. Jackson, P. 1992. La vida en las aulas. Madrid: Morata.

Landow, G. 1995. Hipertexto. La convergencia de la teoría crítica contemporánea y la tecnología. Barcelona: Paidós.

Lerner, D. 1996. Es posible leer en la escuela. En: Lectura y Vida [online] 17 (1) pp. 2-20, marzo 1996. [citado 23 de noviembre 2008]. Disponible en Internet: <http://www.oei.es/fomentolectura/ es_posible_leer_en_la_escuela_lerner.pdf>

Litwin, E. 2005. Las configuraciones didácticas. Una nueva agenda para la enseñanza superior. Buenos Aires: Paidós.

Litwin, E. 2008. El oficio de enseñar. Condiciones y contextos. Buenos Aires: Paidós.

Martínez Barrientos, C. 2003. Formación de hábitos lectores y plan lector. [online] [citado 15 de enero 2008]. Disponible en Internet: <http://www.educared.pe/modulo/upload/134830318.doc>

Meirieu, P. 1992. Aprender sí, pero ¿cómo? Barcelona: Octaedro.

Millán, J.A. 2000. La lectura en la sociedad del conocimiento [online] Madrid: Federación de Gremios de Editores de España. Versión Web 15 de marzo de 2004. [citado 2 de febrero 2011] Disponible en Internet: http://jamillan.com/lecsoco.htm

Minzi, V. 2008-2009. TIC en la escuela como políticas de inclusión de niños y jóvenes. En: Revista Novedades Educativas (216/217), pp. 54-58.

Nemirosky, M. s.f. ¿Problemas o procesos de aprendizaje? Artículo presentado en Enseñar a escribir y leer. II Jornadas. Aragón, España. 2005. Accedido el 30 de diciembre, 2007, desde <http://www.educa.aragob.es/cprzara2/leer/cap1_1/htm>

Orellana, R. s.f. Estrategias para la enseñanza y aprendizaje de la lectura y la escritura [online] [citado 30 de diciembre 2007]. Disponible en Internet: <http:// www.monografias.com/ trabajos45/estrategias-lecto-escritura/estrategias-lecto-escritura.shtml>

Perkins, D. 2001. La escuela inteligente. Del adiestramiento de la memoria a la educación de la mente. Barcelona: Gedisa.

Petit, M. 2006. Lecturas: del espacio íntimo al espacio público. $2^{\circ}$ ed. México: F.C.E.

Prats I., Fernández, M. A. El uso de las TIC en la educación obliga a cambiar las metodologías didácticas y la organización de los centros. En: Educaweb [online]. Monográfico № $179-$ TIC y Educación. [Citado 01 de diciembre 2008]. Disponible en Internet: http://www.educaweb. com/esp/servicios/monografico/ticieducacion_2008/

Ratto, P. Algunas claves para la formación de lectores críticos en la escuela. En: Ratto, P., et al. 2003. El hábito lector. Goce estético y comprensión del mundo. Buenos Aires: Centro de Publicaciones Educativas y Material Didáctico, pp. 9-27.

REALACADEMIA ESPAÑOLA. 2001. Diccionario de la lengua española. $22^{\circ}$ ed. Madrid: Espasa.

Santos Guerra, M. Á. 2000. La escuela que aprende. Madrid: Morata.

Sarto, M.1985. La animación a la lectura. Madrid: SM. 
Schlemenson, S. 2005. Leer y escribir en contextos sociales complejos: aproximaciones clínicas. $3^{\circ}$ ed. Buenos Aires: Paidós.

Solé, I.1992. Estrategias de lectura. Barcelona: Graó.

Tonucci, F. 1989. El nacimiento del lector. [online]. [citado 5 de enero 2008]. Disponible en Internet: <http://www. centros5.pntic.mec.es/cap.getafe/Infantil/F.Tonucci.Nacimiento_del_ lector>

Vigotsky, L. 1995. Pensamiento y lenguaje. Barcelona: Paidós.

Wittrock, M. 1989. La investigación en la enseñanza I, II. Barcelona: Paidós.

* Este artículo se enmarca en la tesis de maestría de la autora, dirigida por la Dra. Silvia Coiçaud. Año 2009

** Master en Educación, Universidad ORT Uruguay. Diploma en Educación, Universidad ORT Uruguay. Profesora de Educación Media, especialidad Literatura, ANEP. Subdirectora, Escuela Técnica de Dolores. 